\title{
Política de igualdade racial na realidade cearense
}

Racial equality policy in Ceará, Brazil

Maria Zelma de Araújo Madeira*

Resumo - Este artigo tem o propósito de refletir acerca das especificidades que assumem o racismo e as desigualdades raciais na cena contemporânea, bem como as estratégias adotadas para enfrentá-los no âmbito das políticas públicas, tendo como fio condutor o registro significativo das principais ações desenvolvidas pela Coordenadoria Especial de Políticas Públicas para Promoção da Igualdade Racial do estado do Ceará (Ceppir), no período de 2015 a 2018. Por fim, serão elucidadas as especificidades e o movimento empreendido para a constituição de uma política pública de caráter transversal na realidade cearense.

Palavras-chave: racismo; desigualdades raciais; política de promoção da igualdade racial.

\begin{abstract}
This article aims to reflect on the specificities of racism and racial inequalities in the contemporary scene, as well as the strategies adopted to address them within the scope of public policies. Its main thread is the remarkable records of the main actions developed by the Special Coordination os Public Policies for the Promotion of Racial Equality of the state of Ceará, Brazil (Ceppir, in Portuguese), between 2015 and 2018. Finally, the local characteristics and the moves taken for the constitution of a transversal public policy in Ceará will be elucidated. Keywords: racism; racial inequalities; policies for the promotion of racial equality.
\end{abstract}

\footnotetext{
* Doutora em Sociologia pela Universidade Federal do Ceará, Brasil. Professora do curso de Serviço Social da UECE, Brasil. Coordenadora da Coordenadoria Especial de Políticas Públicas para a Promoção da Igualdade Racial do Ceará. E-mail: zelmadeira@yahoo.com.br. ORCID: https://orcid.org/0000-0003-2291-4455.
} 


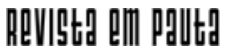

\} POLÍTICA DE IGUALDADE RACIAL - MADEIRA, M. Z. A. \}

DOI: $10.12957 /$ REP.2020.47221

\section{Introdução}

A política de igualdade racial no Brasil possui raízes nas mobilizações populares do movimento negro, e, desse modo, atender às demandas apresentadas significa democratizar o poder público. Nesse sentido, são elucidativas as palavras de Jaccoud $(2009$, p. 11) quando trata do debate público do tema da igualdade racial:

[...] Este debate foi apresentado à sociedade brasileira pelo movimento negro, que defendeu, de forma renovada nas últimas décadas, a necessidade não apenas de combater o racismo, mas de efetivar instrumentos de promoção da igualdade racial. Tais demandas provocaram a ampliação do reconhecimento da relevância do tema do racismo e da discriminação racial como fenômenos sociais ativos na sociedade brasileira, diante do qual, entretanto, levantaram-se resistências e oposições.

Para o enfrentamento do racismo e das desigualdades raciais, fazem-se necessárias as políticas de cunho universal, direcionadas a todos os cidadãos sem qualquer distinção, mas também as políticas específicas, voltadas aos grupos historicamente discriminados em termos raciais na sociedade. As políticas de promoção da igualdade racial no Brasil têm natureza essencialmente transversal, o que significa dizer que sua efetividade depende de uma incidência direta nas diversas esferas da vida social da população. E, para isso, é necessário que todas as políticas setoriais assumam em suas ações o objetivo de reduzir as desigualdades raciais (SANTOS; SILVEIRA, 2010).

As políticas sociais universais demonstraram, ao longo dos anos, sua ineficiência ou fraca incidência na redução das desigualdades raciais e superação do racismo. Diante disso, o movimento negro, por meio das mais diversas formas de organização e reivindicação, tem influenciado no país a formulação de políticas específicas voltadas à promoção da igualdade racial.

Contudo, os quase quatro séculos de escravidão, a disseminação do mito da democracia racial e a naturalização das hierarquias raciais não são entraves históricos fáceis de serem superados. São tarefas urgentes a luta pela efetividade dos marcos legais da política de promoção da igualdade racial, pela sua consolidação de forma participativa em níveis cada vez mais democráticos, pela institucionalização da política por meio de maior transversalidade e com a descentralização e o aperfeiçoamento dos mecanismos de gestão. Dessa maneira, permanecem na agenda política quando se intenciona superar o racismo.

Nesse sentido, a análise proposta aqui acerca da implementação de políticas públicas de promoção da igualdade racial no Ceará demanda um 
conjunto de reflexões sobre as particularidades da questão social brasileira. É fundamental enxergar o Estado brasileiro em sua forma institucional e histórica: construído como mecanismo para manutenção de um capitalismo dependente, para concentração de riqueza e com base em um racismo estrutural.

Em que pese a pertinência desse debate, a execução dessa política pública está subordinada aos ditames do sistema capitalista, e os agentes que nela atuam são desafiados a compreendê-la em suas contradições, limitações e potencialidades.

Nesse ponto, a promoção da igualdade racial, assim como outras políticas transversais, resguarda ainda mais peculiaridades. Além dos obstáculos inerentes aos processos de planejamento setoriais e dos limites dos instrumentos atuais, há que se considerar que a gestão do tema racial como objetivo transversal é especialmente desafiadora. O propósito não se restringe a ampliar a dotação e aprimorar as ações dos órgãos incumbidos de coordenar a política. O mais importante é garantir que todas as demais políticas sejam sensíveis ao objetivo de reduzir as desigualdades raciais e que procurem incluir, em suas ações setoriais, este desígnio. (SILVA et al., 2011, p. 3).

Diante disso, propomos, com este estudo, apresentar uma sistematização das ações realizadas pela Coordenadoria Especial de Políticas Públicas para Promoção da Igualdade Racial (Ceppir), no período de 2015 a 2018, no Ceará, com vistas a compreender as especificidades que assumem as desigualdades raciais, o racismo e o movimento empreendido para a constituição de uma política pública de caráter transversal e com controle social.

\section{Desigualdades raciais como expressão da questão social}

A escravidão no Brasil foi um sistema cujo modo de produzir colonial permitia o tratamento de negros(as) como objetos. A superexploração do trabalho, marcado por uma desumanização jamais conhecida na história da humanidade, forjou as bases do nosso modo de produzir e distribuir riquezas. Como último a abolir a escravidão mercantil, este país, de extensão continental, contou com escravizados espalhados pelos quatro cantos, sofrendo perversidade e violência extrema.

O escravismo não se transformou apenas num sistema econômico, mas também forjou mentalidades, afetou conceitos, moldou os "jeitos de ser" na sociedade por meio dos significados, símbolos e linguagens que subalternizam até hoje os descendentes dos escravizados.

O Brasil recebeu $40 \%$ dos africanos que compulsoriamente deixaram seu continente para trabalhar nas colônias agrícolas da América portuguesa, sob regime de escravidão, num total de cerca de 3,8 milhões 


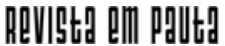

\} POLÍTICA DE IGUALDADE RACIAL - MADEIRA, M. Z. A. \}

DOI: $10.12957 /$ REP.2020.47221

de imigrantes. Hoje, com $60 \%$ de sua população composta de pardos e negros, o Brasil pode ser considerado o segundo mais populoso país africano, depois da Nigéria. Além do mais, e a despeito dos números controversos, estima-se que em 1500 a população nativa girasse em torno de 1 milhão a 8 milhões, e que o 'encontro' com os europeus teria dizimado entre 25\% e 95\%. (SCHWARCZ; STARLING, 2018, p. 15).

No pós-abolição e início do século XX assistiu-se tensões raciais em que os ex-cativos não foram tratados como classe laboriosa, nem classe trabalhadora, nem sequer puderam compor o exército industrial de reserva, foram classificadas como classes perigosas. A narrativa dominante proclamava que estes não eram qualificados suficiente para ajudarem a erguer os pilares da futura nação. O Estado Nacional favoreceu a política migratória, importando mão-de-obra apta ao novo processo de produção, sob a alegação de se resolveria o problema da falta de trabalhadores(as) qualificados(as) e, ao mesmo tempo, evitaria a degenerescência da nação, branqueando-a. Egressos das senzalas, foram encurralados a viver nas áreas mais precárias, compondo a grande franja de marginalizados criada pelo modo de produção que surgia. (GONÇALVES: 2018)

Essa formação econômica, social, cultural e política nunca foi desestruturada. Sua estruturação se deu em um direcionamento bem definido: branco, elitista e patriarcal. Além disso, segue a perpetuar-se contemporaneamente de diferentes formas, com consequências que podem ser observadas nas persistentes desigualdades sociorraciais e por atitudes naturalizadoras do racismo - racismo esse estruturante da modernidade e obstáculo à igualdade. Nas palavras de Silvio de Almeida (2018, p. 16), "o racismo fornece o sentido, a lógica e a tecnologia para as formas de desigualdade e violência que moldam a vida social contemporânea".

O Brasil atual segue com as ideias e práticas racistas, falhando na disposição de garantia de direitos. Para muitos, o racismo aqui é leve, pois não vigorou o apartheid. Quando acontece, e se acontece, não passa de um fato isolado, um problema psicológico, um fenômeno ético de caráter individual ou coletivo. Temos um racismo sem agentes e uma "autoconcepção de que não é violento" (SCHWARCZ; STARLING, 2018). O país não superou a escravidão, que se reedita sem sistema formal, mas como produção coletiva que naturaliza as desigualdades e discriminações sociorraciais.

Em resumo: o racismo é uma decorrência da própria estrutura social, ou seja, do modo 'normal' com que se constituem as relações políticas, econômicas, jurídicas e até familiares, não sendo uma patologia social e nem um desarranjo institucional. O racismo é estrutural. Comportamentos individuais e processos institucionais são derivados de uma sociedade cujo racismo é regra e não exceção. [...] Nesse caso, além de medidas que coíbam o racismo individual e institucionalmente, torna-se imperativo refletir sobre mudanças profundas nas relações sociais, políticas e econômicas. (ALMEIDA, 2018, p. 38-39). 
As expressões do racismo se apresentam concretamente na organização política, econômica e jurídica de nossa sociedade. É válido destacar que a designação de seu caráter "estrutural" não significa afirmar uma situação imutável, que ações e políticas antirracistas sejam infrutíferas ou mesmo que os sujeitos que praticam atos racistas devam ser eximidos de sua responsabilidade. "O propósito desse olhar mais complexo é afastar as análises superficiais ou reducionistas sobre a questão racial, que além de não resolverem o problema dificultam em muito o combate ao racismo" (ALMEIDA, 2018, p. 39).

A passagem do sistema escravista para o trabalho livre no capitalismo possibilitou aos que não interessava efetivar políticas de promoção da igualdade racial afirmar a existência de uma suposta garantia da universalidade da lei e de igualdade perante a ela. O escasso debate acerca do racismo no Brasil foi limitado a conflitos do âmbito do privado e das relações interpessoais, difícil de identificar e mais ainda de punir.

Para Jessé Souza (2017), no fim do século XIX ocorreram transformações fundamentais no país que geraram a criação da "ralé de novos escravos" como continuação da escravidão no Brasil moderno. Embasado em reflexões sobre o clássico $A$ integração dos negros na sociedade de classes, de Florestan Fernandes, o autor elucida: o quadro geral da sociedade de classes que se cria depois da escravidão apresentava o seguinte formato: no topo da hierarquia social, a preservação e reprodução do poder estavam nas mãos das antigas famílias proprietárias rurais de cafeicultores, com pouco espaço de competição; abaixo da aristocracia rural que se moderniza, o estrangeiro aparece como a grande esperança nacional de progresso, ou seja, os imigrantes, principalmente os italianos, e os de origem nacional mais instruídos eram considerados os candidatos naturais a ocuparem os postos de trabalho livre.

Abaixo dos novos segmentos incluídos no mercado competitivo de trabalho estava a plebe nacional, composta por brancos pobres que vinham do campo para a cidade. E, mais abaixo ainda, estava o segmento que Jessé Souza (2017, p. 77) denomina "ralé brasileira",

[...] composta pelos negros recém-libertos e por mulatos e mestiços de toda ordem para quem a nova condição era apenas uma nova forma de degradação. A submersão na lavoura de subsistência ou a formação das favelas nas grandes cidades passam a ser o destino reservado pelo seu abandono. Temos aqui a constituição de uma configuração de classes que marcaria a modernização seletiva e desigual brasileira a partir de então. Para o negro, sem a oportunidade com chances reais na nova ordem, restavam os interstícios do sistema social: a escória proletária, o ócio dissimulado ou a criminalidade fortuita ou permanente [...].

Os dados atuais traduzem em números as consequentes desigualdades forjadas pelo racismo estrutural na sociabilidade brasileira. Segundo a PNAD (IBGE, 2018), das 12,8 milhões de pessoas desempregadas no Brasil, 


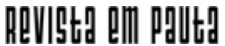

\} POLÍTICA DE IGUALDADE RACIAL - MADEIRA, M. Z. A. \}

DOI: $10.12957 /$ REP.2020.47221

$(64,6 \%)$ são negras. Quanto ao rendimento de trabalhadores(as) negros(as), ele foi de $R \$ 1.608,00$, e o dos brancos foi de $R \$ 2.796,00$. Quase metade da população negra $(46,9 \%)$ está na informalidade, enquanto entre os brancos é de 33,7\%. (IBGE,2019). Logo, os dados revelam que o racismo se inscreve nos índices de desigualdades em áreas estratégicas para processos de desenvolvimento social e econômico.

Quanto ao nível de escolaridade, em 2015,18\% dos pretos e pardos não possuíam instrução, em contraposição a $4 \%$ dos brancos. Além disso, $59 \%$ da população negra possuía o fundamental incompleto, enquanto que brancos correspondem a $21 \%$ das pessoas com fundamental incompleto (IBGE, 2017).

De acordo com o Atlas da Violência (CERQUEIRA, 2018), em um período de uma década, entre 2006 e 2016, a taxa de homicídios de negros cresceu $23,1 \%$. No mesmo período, a taxa entre os não negros teve uma redução de $6,8 \%$ e a taxa de homicídios de mulheres negras foi $71 \%$ superior à de mulheres não negras. O patriarcado e o racismo construíram um lugar diferenciado de inferioridade para as mulheres negras: estas ainda têm muito a trilhar para serem vistas como sujeitos plenos.

Segundo o Atlas da Violência (CERQUEIRA, 2018), os jovens negros estão entre as maiores vítimas de mortes violentas. Sete em cada dez vítimas são negras, a maioria jovem e do sexo masculino. Esses jovens têm se deparado cotidianamente com a herança do escravismo, convivendo com o peso da "criminalidade mestiça" como particularidade nacional, suas condutas identificadas como delituosas. São frequentes as narrativas que os colocam numa condição de inferioridade como pretos, pobres e de periferia. Isso os desumaniza como sujeitos capazes de construir caminhos e práticas de reinvenção de sua existência.

É nos territórios periféricos que a desigualdade sociorracial, a falta de segurança pública, o racismo institucional e a violência letal deitam suas raízes. Porém, nesses mesmos territórios surgem expressões de resistências culturais e políticas por parte da juventude que constrói experiências de sociabilidade e lutas alternativas e descolonizadoras, por meio de uma diversidade de linguagens e intervenções - meios de comunicação digitais, fotografias, cinema, música, teatro e outras expressões artísticas e culturais com o potencial de estimular novas formas de comunicação e educação (NOGUEIRA, 2017).

Numa conjuntura desafiante à pauta dos direitos humanos, têm importância os ativos políticos que possam fortalecer os perfis identitários de pertença racial, com incentivo às experiências democráticas que fomentem processos de emancipação dos grupos populacionais historicamente discriminados por questões étnicas e raciais na escolha dos seus destinos. 


\section{A política de promoção da igualdade racial no Brasil}

A consolidação da política nacional de promoção da igualdade racial vincula-se às mobilizações populares do movimento negro, principalmente no período de redemocratização. Os sujeitos políticos inseridos nas organizações negras, partidos políticos, mídia e outros grupos de pressão denunciaram o racismo e exigiram com urgência uma ação coletiva pública.

Logo, essa política pública, constituída historicamente por meio de relações sociais tensionadas e permeadas de contradições, é de recente inserção na agenda governamental e legislativa. Apenas em 1988 foi criado o primeiro órgão federal dedicado à questão racial - a Fundação Cultural Palmares, voltada, no entanto, à temática cultural. Ações históricas como a Marcha Zumbi dos Palmares Contra o Racismo, pela Cidadania e a Vida, em 1995, proporcionaram maior visibilidade à pauta e forçaram o governo brasileiro a reconhecer oficialmente, pela primeira vez, a existência do racismo no país.

Foi somente a partir do governo de Fernando Henrique Cardoso (1995-2003) que o Estado brasileiro reconheceu, institucionalmente, a existência da desigualdade etnicorracial e, então, criou o Grupo de Trabalho Interministerial pela Valorização da População Negra. "O combate ao racismo transcendeu da denúncia para o reconhecimento de sua existência e, finalmente, para ser incluído na dimensão institucional das políticas públicas" (OLIVEIRA, 2016, p. 32).

É importante elucidar aqui que existem diferentes tipos de políticas de promoção da igualdade racial. Essas podem ocorrer por meio de políticas universais ou por meio de políticas especificamente direcionadas aos grupos discriminados racialmente no Brasil. Em relação a esta última, existem ao menos três tipos de políticas ou ações de combate ao racismo e às desigualdades raciais que merecem destaque: as repressivas, as valorativas e as afirmativas.

As políticas repressivas ${ }^{1}$ buscam combater o ato discriminatório através da legislação criminal existente. As valorativas ${ }^{2}$ referem-se às ações ou políticas que reconhecem ou valorizam a pluralidade étnica e buscam desconstruir estereótipos racistas que marcam a sociedade brasileira, tendo caráter permanente e focalizado, diferente do terceiro tipo: as ações afirmativas, ${ }^{3}$ que são de caráter temporário e direcionado ao grupo étnico discriminado. Esta última possui o intuito de oportunizar o acesso a direitos

\footnotetext{
${ }^{1}$ São exemplos: a Constituição Federal (CF) de 198............................... no seu Art. 5 , Inciso XLII , que determina que "a prática do racismo constitui crime inafiançável e imprescritível, sujeito de reclusão nos termos da lei", e a Lei no 7.716 / 1989 que define os crimes resultantes de preconceito de raça ou de cor, comumente conhecida por Lei Caó, que regulamenta aquilo que preceitua a CF.

${ }^{2}$ São exemplos: as leis $n^{\circ} 10.639 / 2003$ (BRASIL,2003) e $n^{\circ} 11.645 / 2008$ (BRASIL,2008), que tornam obrigatório o ensino da cultura e história dos africanos, afro-brasileiros e indígenas nos currículos escolares.

${ }^{3}$ Como a Lei das Cotas sociais e raciais nas universidades federais, Lei no 12.711/2012 (BRASIL, 2012), nas universidades estaduais, Lei 16.197/2017 (CEARÁ, 2017), e das cotas para os concursos públicos, Lei nº 12.990/ 2014 (BRASIL,2014) que reservam $20 \%$ das vagas para os que se autodeclaram negros.
} 


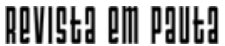

\} POLÍTICA DE IGUALDADE RACIAL - MADEIRA, M. Z. A. \}

DOI: $10.12957 /$ REP.2020.47221

sociais e ampliar a participação nos setores sociais em que a discriminação étnico-racial dificultou seu desenvolvimento ou os excluiu (SANTOS; SILVEIRA, 2010).

A formulação e prática dessas políticas ganharam maior espaço e força a partir dos anos 2000, com o início do Governo Luiz Inácio Lula da Silva. Em 2003, foi criada a Secretaria Especial de Políticas de Promoção da Igualdade Racial (Seppir), com status de ministério e tendo como objetivo formular e coordenar políticas e articular ações do governo federal de combate à discriminação e à desigualdade racial.

Foram criados, ainda, o Conselho Nacional de Promoção da Igualdade Racial (CNPIR) e o Fórum Intergovernamental de Promoção da Igualdade Racial (Fipir). Passaram a ser realizadas as Conferências Nacionais de Promoção da Igualdade Racial, tendo ocorrido a primeira em 2005 e a segunda em junho de 2009. A terceira ocorreu em 2013 e a quarta em maio de 2018 (JACCOUD, 2009).

Em 2010 foi criado o Estatuto da Igualdade Racial, Lei ${ }^{\circ} 12.288$ (BRASIL, 2010), importante marco legal ao definir discriminação racial como a exclusão, distinção, restrição ou preferência baseada na etnia, descendência ou origem nacional. Estabeleceu, também, a desigualdade como sendo toda situação injustificada de diferenciação de acesso e de oportunidades em virtude de etnia, descendência ou origem nacional.

O Brasil conta com 16 anos de política de igualdade racial sob o comando da Secretaria Nacional de Promoção da Igualdade Racial (Seppir). Entretanto, como bem elucida Behring (2009, p. 315-316), as políticas sociais são concessões/conquistas mais ou menos elásticas, a depender da correlação de forças na luta política entre os interesses das classes sociais e seus segmentos envolvidos na questão. No período de expansão, a margem de negociação se amplia; na recessão, ela se restringe.

No decorrer desse curto período de institucionalização de ações governamentais para o combate ao racismo e redução das desigualdades raciais, alguns elementos têm imposto entraves para a consolidação das ações governamentais ao formato de política pública. Conforme Theodoro (2008), dentre as dificuldades encontradas para a efetivação de políticas públicas de temática étnico-racial, destacam-se: o caráter residual dessas políticas, com poucos investimentos e fragmentação dos programas e ações; ausência de uma base conceitual para a formulação dos programas e ações que proporcionem, dentro das próprias instâncias do Estado, entendimento sobre o caráter estrutural do racismo; a insuficiente compreensão da conexão entre as desigualdades étnico-raciais e as desigualdades sociais; bem como o racismo institucional, que promove a desigualdade étnico-racial por meio da oferta hierarquizada dos serviços, benefícios e oportunidades.

Dito em outros termos, a construção da questão racial como campo de intervenção política, no Brasil, ainda está por ser concluída. [...] O Estado 
tergiversa, afirmando a existência da desigualdade racial, ao mesmo tempo em que não prioriza programas e ações nesse domínio. Além disso, uma parcela da sociedade insiste em não identificar essa temática como um problema, e a parte que o faz mantém-se dividida entre aqueles que advogam pela necessidade da ação do Estado e o reconhecimento da questão racial, e os que, de outro lado, postulam, ao que se entende, equivocadamente, a suficiência da perspectiva universalista e do tratamento igualitário para o enfrentamento das desigualdades e para a própria estabilidade da democracia. O recente debate sobre as cotas para negros nas universidades, em sua forma e conteúdo, é o exemplo mais emblemático de tal embate. (THEODORO, 2008, p. 177).

O contexto político e econômico é definidor para a consolidação do que está previsto nos marcos legais da política de promoção da igualdade racial. O contexto iniciado a partir do impeachment da presidenta da República Dilma Rousseff em 2016, materializado por meio de um golpe de Estado jurídico-parlamentar que destituiu a presidenta e empossou o vicepresidente Michel Temer, foi definidor para o aprofundamento de ações de desmonte das políticas sociais e subtração de direitos sociais.

Construindo uma 'base social' conservadora, reacionária e, por vezes, filofacista, a direita precisou concluir a sua contrarreforma liberal do Estado iniciada nos anos 1990, abater as ideologias do trabalho, as conquistas libertárias das mulheres, as étnico-raciais, LGBT, bem como os embriões de emancipação política (ainda que tênues), dotando seus conteúdos de novos significados em prol da sua direção político-social e moral, cujos principais aspectos, como já referidos, podem ser identificados no combate à corrupção, no fetiche do Judiciário, na austeridade fiscal, no machismo e no branqueamento do poder, para falar nos principais. (MOTA, 2017, p. 44).

Merece destaque a própria situação da Secretaria de Promoção da Igualdade Racial, criada por meio da Lei no 10.678 de 23 de maio de 2003. Em 5 de abril de 2016, a Lei no 13.266 extinguiu a Secretaria de Política de Promoção da Igualdade Racial da Presidência da República e criou o Ministério das Mulheres, da Igualdade Racial, da Juventude e Direitos Humanos. Também em 2016, a Lei no 13.341 de 29 de setembro de 2016 extingue o Ministério das Mulheres, da Igualdade Racial, da Juventude e dos Direitos Humanos. Na estrutura do Ministério das Mulheres, Família e Direitos Humanos, pelo Decreto no 9.673 de 2 de janeiro de 2019, essa secretaria passa a ser denominada Secretaria Nacional de Políticas de Promoção da Igualdade Racial (SNPIR), contando apenas com dois departamentos: o Departamento de Igualdade Racial (Depir) e o de Promoção da Igualdade Racial, e o Departamento de Promoção da Igualdade Racial para Povos e Comunidades Tradicionais (Decomt). O ano de 2019 inicia com essa instituição de grande relevância nacional rebaixada em seu status institucional e fragilizada em seu quadro profissional. 


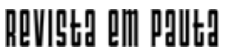

\} POLÍTICA DE IGUALDADE RACIAL - MADEIRA, M. Z. A. \}

DOI: $10.12957 /$ REP.2020.47221

Toda política pública é um canal de intervenção na sociedade para assegurar direitos e reduzir desigualdades, e a política de promoção da igualdade racial não assume função diferente. O propósito é melhorar a eficiência do setor público na efetivação da política de promoção da igualdade racial, elaborando de forma sistemática uma gestão coerente com o enfrentamento ao racismo, com metas explícitas de redução das desigualdades sociorraciais e ações de fortalecimento/reconhecimento identitários desses grupos étnico-raciais discriminados, por meio de estratégias da transversalidade nas políticas setoriais, do eixo da descentralização e do controle social.

Silva (2018, p. 148) afirma o seguinte sobre as políticas de promoção da igualdade racial:

[...] Avalia-se que, embora se tenham avanços no domínio estrutural, esses ainda não parecem ser dotados de robustez suficiente para o enfrentamento da questão, tanto porque são resultados de conflitos e conciliações que alteram seu escopo, como porque os progressos nos domínios disciplinar e hegemônico parecem ainda não ter alcançado o mesmo patamar.

Logo, não restam dúvidas de que a organização de instituições, agentes públicos e participação da sociedade no controle social são elementos essenciais à consolidação dessa política. O desafio atual é assegurar o reconhecimento da relevância da política de promoção da igualdade racial e a responsabilidade do Estado em intervir nas desigualdades raciais e no combate ao racismo. É necessário assegurar que a perspectiva racial esteja nos processos de planejamento, monitoramento e avaliação das políticas públicas, de forma a alcançarmos a equidade no acesso a oportunidades de diversos grupos raciais e sociais (JACCOUD, 2009).

\section{A política de promoção da igualdade racial no Ceará}

No Ceará, de acordo com a PNAD Contínua (IBGE, 2018), a população por cor ou raça está assim distribuída do total de 9.073 milhões: 2.561 milhões se autoafirmam brancos (28,23\%); 480 mil, pretos (5,29\%); e 5.962 milhões, pardos $(65,71 \%)$ (IBGE, 2018). Essas categorias não conseguem expressar as identidades étnico-raciais dos brasileiros, e desde o primeiro recenseamento em 1872 o sistema de classificação é praticamente o mesmo. A população negra (pretos e pardos) totaliza $71 \%$.

É notável o fenômeno da pardalização no Estado. O termo pardo é maioria - corresponde a $65,71 \%$ - e remete à miscigenação de origem preta ou indígena; como coringa, agrega infinitas nomenclaturas numa mistura de fenótipo e descendência, recheada de indefinições. Captura todos aqueles que não se enquadram nas outras categorias, mas não é usado pela 


\section{Revilgta am pallt}

\} POLÍTICA DE IGUALDADE RACIAL - MADEIRA, M. Z. A. \}

DOI: $10.12957 /$ REP.2020.47221

maior parte da população. Como grande guarda-chuva, abriga ambiguidades, evitando um debate crítico e propositivo de classificação racial, em que negros e indígenas não sejam invisíveis, e que não impeça o estudo das desigualdades entre brancos e não brancos.

Para fins de formulação, execução, monitoramento e avaliação de políticas públicas voltadas ao enfrentamento das desigualdades raciais, faz-se necessário compreender os processos que resultaram na exclusão social e na discriminação racial, bem como a herança e recriação da escravidão, os impactos do racismo estrutural e a necessidade de revelar as diversas composições étnicas em todas as regiões do Brasil.

No Ceará, a abolição da escravatura ocorreu em 25 de março em 1884, quatro anos antes da Lei Áurea - desse modo, isso dá base ao discurso de inexistência de negros(as), provocando a invisibilidade desse grupo étnico no Ceará. Contudo, os indicadores sociais e econômicos têm revelado sua existência em lugares de vulnerabilidade, de desigualdades sociorraciais, como alvo das práticas persistentes do racismo.

Esses problemas são colocados na sociedade e demandam atenção por parte do poder público, quando incluídos na agenda governamental, por meio das políticas transversais de promoção da igualdade racial. O Governo do Estado do Ceará criou, em 2010, a Coordenadoria Especial de Políticas Públicas para a Promoção da Igualdade Racial (Ceppir), ${ }^{4}$ tendo sua estruturação se efetivado no ano de 2011. Dentre as competências da Ceppir, destacam-se inicialmente: assessorar a direção e gerência superior do Gabinete do Governador em assuntos relacionados às políticas para a promoção da igualdade racial; coordenar a formulação e implementação de políticas públicas e de diretrizes para a promoção da igualdade racial no estado do Ceará; articular ações governamentais de enfrentamento e combate à discriminação racial de indivíduos e grupos étnicos, com ênfase na população negra, nas comunidades quilombolas, indígenas, povos de terreiro (religiões de matriz africana e afro-brasileira), ciganos e demais comunidades tradicionais, entre outras. A Coordenadoria esteve até o final de 2018 vinculada à estrutura do Gabinete do Governador do estado do Ceará. Com a reforma administrativa, ${ }^{5}$ atualmente faz parte da estrutura da Secretaria da Proteção Social, Justiça, Cidadania, Mulheres e Direitos Humanos (SPS).

Entre as ações voltadas para promoção da igualdade racial, a Ceppir desenvolveu, no período de 2015 a 2018: ações de fortalecimento institucional de órgãos e conselhos de promoção da igualdade racial, tanto em âmbito estadual quanto municipal; capacitações e articulação com movimentos sociais para fortalecer a implementação de políticas públicas e o enfrentamento ao racismo e à discriminação racial; reuniões de articulação política

\footnotetext{
${ }^{4}$ Em janeiro de 2010, o governador do Estado do Ceará propôs, através de mensagem encaminhada à Assembleia Legislativa, alteração da Lei Estadual no 13.875/07. Com o Decreto no 31.073 de 11 de dezembro de 2012, define-se as competências da Ceppir.

${ }^{5}$ Reforma administrativa pela Lei no 16.710 , de 21 de dezembro de 2018 (DOE 27/12/2018), que dispõe sobre o modelo de gestão do Poder Executivo e altera a estrutura da administração estadual.
} 


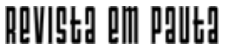

\} POLÍTICA DE IGUALDADE RACIAL - MADEIRA, M. Z. A. \}

DOI: $10.12957 /$ REP.2020.47221

e institucionais com secretários e gestores estaduais e municipais visando fomentar políticas públicas de igualdade racial de forma transversal, por meio de aprovação e execução de Monitoramento de Ações e Programas Prioritários (Mapp) voltados a projetos produtivos e outras ações de reconhecimento identitários desses grupos; criação e implementação do Conselho Estadual de Promoção da Igualdade Racial (Coepir); iniciativas voltadas para a educação escolar indígena, quilombola e implementação das leis no 10.639/ 2003 e 11.645/2008; e acompanhamento e encaminhamento para resolução de conflitos fundiários e regularização dos territórios das comunidades indígenas e quilombolas.

Em 2015 foi celebrado um convênio para execução do projeto Municipalizando a Promoção da Igualdade Racial no Ceará, realizado junto à Secretaria Especial de Políticas para Promoção da Igualdade Racial do Governo Federal. O objetivo era fortalecer os municípios na superação do racismo e desigualdades e subsidiar os municípios com orientações para o funcionamento de conselhos, planos e órgão de promoção da igualdade racial.

Foi criado o Conselho Estadual de Promoção da Igualdade Racial (Coepir) como instância de máxima importância para a efetivação do controle social e promoção de diálogo entre governo e sociedade, por meio da Lei $\mathrm{n}^{\mathrm{o}}$ 15.953, de 14 de janeiro de 2016 (CEARÁ, 2016), funcionando efetivamente na primeira gestão (2016-2018) e na segunda, de 2018 até 2020. O Coepir é um órgão de caráter normativo, consultivo e de deliberação colegiada, composta por representantes do governo e da sociedade civil organizada. Possui a finalidade de acompanhar e deliberar critérios e parâmetros para a implementação de metas e prioridades para assegurar as condições de igualdade à população negra, indígenas, quilombolas, ciganos e povos de terreiro.

Com ênfase nos processos participativos de fortalecimento da esfera pública, em 2017 foi realizada a IV Conferência Estadual de Promoção da Igualdade Racial, como também oito conferências macrorregionais, com a finalidade de conferir o que vem sendo realizado e propor novas iniciativas que melhorem os serviços públicos prestados aos povos indígenas, quilombolas, de terreiro, ciganos e população negra (CEARÁ, 2017a). O tema da conferência foi: Reconhecimento, Justiça e Desenvolvimento na Década dos Afrodescendentes, com foco na equidade entre as pessoas e na superação do racismo.

Considerou-se relevante realizar capacitação de servidores com enfoque no combate ao racismo institucional, como forma de reduzir a discriminação dentro das instituições públicas. Por meio de capacitação, visa-se contribuir para que o servidor identifique em seu cotidiano de trabalho como são realizados os atendimentos e implementadas as políticas públicas para os segmentos historicamente discriminados por questões étnicas e raciais. Dentro dessa perspectiva, no período de 2016 a 2018 foram capacitados 


\section{Revilgta am pallt}

\} POLÍTICA DE IGUALDADE RACIAL - MADEIRA, M. Z. A. \}

DOI: $10.12957 /$ REP.2020.47221

servidores estaduais e municipais de diversas áreas, destacando-se: agentes de segurança pública, profissionais da política de educação, gestores municipais, equipes técnicas de nível médio e superior da política de assistência social, discentes e servidores públicos da universidade federal e das estaduais do Ceará.

A partir dessa breve análise das iniciativas da política de igualdade racial no Ceará, foi possível verificar que houve alguns avanços com a criação da Lei no 16.197 de 2017, Lei de Cotas nas universidades estaduais (CEAŔÁ, $2017 b)$. Embora as cotas representem democratização do acesso de grupos étnico-raciais discriminados, temos nos deparado ultimamente com casos de fraudes, e a Ceppir tem realizado articulações junto às universidades estaduais e recomendado a implantação da Comissão de Heteroidentificação, ${ }^{6}$ composta preferencialmente por conhecedores da temática da promoção da igualdade racial e de enfrentamento ao racismo.

Diante da discriminação e sub-representação dessas populações na realidade cearense, urge a efetividade das políticas específicas, ainda que provoquem controvérsias nos quadros institucionais. Sua efetividade rompe com estruturas de reprodução de desigualdades e redefine relações de poder. Assim, em contexto de ameaça aos direitos humanos é preciso ratificar as políticas de igualdade racial na garantia de direitos e na codificação de valores civilizatórios.

\section{Considerações finais}

A inserção do tema racial é recente na agenda governamental brasileira, datando do início dos anos 2000. Ainda ocupa o subterrâneo da esfera governamental, pois convivemos com mecanismos de reprodução do racismo e das discriminações reveladas nas desigualdades raciais no contexto brasileiro. Esse fato guarda forte relação com a negação do racismo sob disseminação do mito da democracia racial, que acaba por naturalizar as hierarquias raciais por meio de silenciamentos e ausências em muitos governos, a insistência no universalismo - somos todos iguais - sem considerar a igualdade material.

O racismo se coloca como grande problema no Brasil. É impossível contar com um país republicano e com uma verdadeira democracia racial se não for desatado esse nó. Portanto, a gestão da política de promoção da igualdade racial tem importância e deve ocupar espaço prioritário na máquina estatal, devendo ser conhecida em seus limites orçamentários, impedindo a ampliação das ações. Diferentemente do que se possa supor, a demanda de

\footnotetext{
6 Tomando como referência a Portaria Normativa $n^{\circ}$ 4, de 6 de abril de 2018, que regulamenta o procedimento de heteroidentificação complementar à autodeclaração dos candidatos negros, para fins de preenchimento das vagas reservadas nos concursos públicos federais, nos termos da Lei n 12.990, de 9 de junho de 2014. (BRASIL,2014)
} 


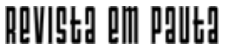

\} POLÍTICA DE IGUALDADE RACIAL - MADEIRA, M. Z. A. \}

DOI: $10.12957 /$ REP.2020.47221

informação racial não traz a apartação. A raça, em termos sociais e políticos, é um fator relevante na promoção de direitos, da política de reconhecimento e revalorização das identidades étnico-raciais. Pode permitir que as pessoas se enxerguem na sua diversidade.

A Ceppir, nesses anos de existência, tem marcado presença nesse estado que historicamente negou a existência de indígenas e da população negra, e ainda se depara com desafios grandiosos para alcançar a igualdade racial. Esse órgão busca alcançar, como resultado temático transversal, indivíduos e grupos étnico-raciais reconhecidos, com proteção contra o racismo e intolerância, com direitos humanos assegurados e socioeconomicamente incluídos. Entretanto, ainda carece de esforços voltados à criação de condições para a garantia da titularidade dos territórios quilombolas e demarcação de territórios indígenas para o desenvolvimento de suas potencialidades econômicas, sociais e culturais.

Torna-se necessária, também, a implementação de políticas de ações afirmativas que garantam representação desses segmentos da força de trabalho na burocracia governamental, nos cargos em comissão e de terceirizados. No âmbito da gestão e desenvolvimento de pessoas, tem relevância a realização de um censo da pertença étnico-racial dos servidores públicos, com o propósito de visualizar os cargos que ocupam na máquina estatal.

Assim, a discriminação racial e o racismo estrutural presentes nas relações sociais são fatores que repercutem nas condições de vida, tais como saúde, educação, inserção no mercado de trabalho, acesso a direitos e serviços sociais básicos. Comprometem os processos de vinculação social, reconhecimento e respeito aos modos de vida associados ao pertencimento racial. As consequências dessas desigualdades sociorraciais se revelam na reprodução da pobreza material, restrição da participação política e isolamento social (SILVA et al., 2018). 


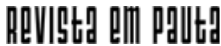

\} POLÍTICA DE IGUALDADE RACIAL - MADEIRA, M. Z. A. \}

DOI: $10.12957 /$ REP.2020.47221

\section{Referências}

ALMEIDA, S. L. de. O que é racismo estrutural? Belo Horizonte: Letramento, 2018.

BEHRING, E. R. Políticas Sociais no contexto da crise capitalista. CFESS; ABEPSS. Serviço Social: direitos sociais e competências profissionais. Brasília: CFESS/ABEPSS, 2009.

BRASIL. Lei no 7.716, de 5 de janeiro de 1989. Define os crimes resultantes de preconceito de raça ou de cor. Disponível em http://www.planalto.gov.br/ ccivil_03/leis/l7716.htm. Acesso em: 29 jun. 2019.

BRASIL. Constituição da República Federativa do Brasil. 1998. Disponível em: http://www.planalto. gov.br/ccivil_03/constituicao/constitui\%C3\%A7ao. html. Acesso em: 29 jun. 2019.

BRASIL. Lei no 10.639, de 9 janeiro de 2003. Altera Lei no 9.394, de 20 de dezembro de 1996, que estabelece diretrizes e bases da educação nacional, para incluir no currículo oficial da Rede de Ensino a obrigatoriedade da temática "História e Cultura Afro-Brasileira", e dá outras providências. Disponível em: http://www.planalto.gov.br/ccivil_03/leis/2003/L10.639.htm. Acesso em: 21 jun. 2019.

BRASIL. Lei $n^{\circ}$ 11.645, de 10 de março de 2008, que altera a Lei no 9.394, de 20 de dezembro de 1996, modificada pela Lei no 10.639, de 9 de janeiro de 2003, que estabelece as diretrizes e bases da educação nacional, para incluir no currículo oficial da rede de ensino a obrigatoriedade da temática "História e Cultura Afro-Brasileira e Indígena". Disponível em http://www.pla nalto.gov.br/ccivil_03/_Ato2007-2010/2008/Lei/L11645.htm. Acesso em: 21 jun 2019.

BRASIL. Lei $n^{\circ} 12.288$, de 20 de julho de 2010. Institui o Estatuto da Igualdade Racial, altera as leis no 7.716 , de 5 de janeiro de 1989, 9.029, de 13 de abril de 1995, 7.347, de 24 de julho de 1985, e 10.778, de 24 de novembro de 2003. 2010. Disponível em: http://www.planalto.gov.br/ccivil_03/_ato20072010/2010/lei/l12288.htm. Acesso em: 29 jun. 2019.

BRASIL. Lei $n^{\circ} 12.711$, de 29 de agosto de 2012. Dispõe sobre o ingresso nas universidades federais e nas instituições federais de ensino técnico de nível médio e dá outras providências. 2012. Disponível em: http://www. planalto.gov.br/ccivil_03/_ato2011-2014/2012/lei/l12711.htm. Acesso em: 29 jun. 2019.

BRASIL. Lei n. 12.990, de 9 de junho de 2014. Reserva aos negros 20\% (vinte por cento) das vagas oferecidas nos concursos públicos para provimento de cargos efetivos e empregos públicos no âmbito da administração pública federal, das autarquias, das fundações públicas, das empresas públicas e 


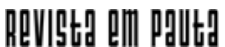

\} POLÍTICA DE IGUALDADE RACIAL - MADEIRA, M. Z. A. \}

DOI: $10.12957 /$ REP.2020.47221

das sociedades de economia mista controladas pela União. Disponível em: http://www.planalto.gov.br/CCIVIL_03/_Ato2011-2014/2014/Lei/L12990.htm Acesso em: 29 jun. 2019.

CEARÁ. Lei Estadual no 13.875, de 7 de fevereiro de 2007 (D.O.07.02.07). Dispõe sobre o Modelo de Gestão do Poder Executivo, altera a estrutura da Administrativa Estadual, promove a extinção e criação de cargos de direção e assessoramento superior, e dá outras providências. Disponível em: https:/ /www.al.ce.gov.br//legislativo/legislacao5/leis2007/13875.htm. Acesso em: 29 jun. 2019.

CEARÁ. Decreto no 31.073, de 11 de dezembro de 2012. Dispõe sobre a estrutura organizacional, a distribuição e a denominação dos cargos de direção superior e de direção e assessoramento do Gabinete do Governador (Gabgov). Disponível em: https://www.jusbrasil.com.br/diarios/44209381/doececaderno-1-12-12-2012-pg-3. Acesso em: 29 jun. 2019.

CEARÁ. Lei no 15.953, de 14 de janeiro de 2016. Institui o Conselho Estadual de Promoção da Igualdade Racial do Estado do Ceará (Coepir). 2016. Disponível em: https://belt.al.ce.gov.br/index.php/legislacao-do-ceara/organizacaotematica/direitos-humanos-e-cidadania/item/3560-lei-n-15-953-de-14-0116-republicado-por-incorrecao-d-o-17-02-16. Acesso em: 29 jun. 2019.

CEARÁ. Lei no 16.197, de 17 de janeiro de 2017 (D.O. 18.01.17). Dispõe sobre a instituição do Sistema de Cotas nas Instituições de Ensino Superior do Estado do Ceará. 2017b. Disponível em: https://www.jusbrasil.com.br/ diarios/134509037/doece-18-01-2017-pg-1. Acesso em: 29 jun. 2019.

CEARÁ. Coordenadoria Especial de Políticas Públicas para Promoção da Igualdade Racial (Ceppir). Relatório da IV Conferência Estadual de Promoção da Igualdade Racial. Fortaleza, 2017a.

CEARÁ. Lei no 16.710, de 21 de dezembro de 2018. Dispõe sobre o modelo de gestão do poder executivo, altera a estrutura da administração estadual. Disponível em https://www.jusbrasil.com.br/diarios/223062866/doece-2112-2018-pg-5. Acesso em: 29 jun. 2019.

CERQUEIRA, D. et al. Atlas da violência. Rio de Janeiro: Ipea, 2018.

GONÇALVES, R. Quando a questão racial é o nó da questão social. Revista Katálysis, Florianópolis, v. 21, n. 3, set./dez. 2018.

IBGE. Pesquisa nacional por amostra de domicílios (PNAD). Rio de Janeiro: IBGE, 2017.

Desigualdades Sociais por Cor ou Raça no Brasil. Estudos e Pesquisas Informação Demográfica e Socioeconômica número 41. Rio de Janeiro: IBGE, 2019.

IBGE. PNAD Contínua 2018. 2018. Disponível em: https://biblioteca. ibge.gov.br/visualizacao/livros/liv101657_informativo.pdf. Acesso em: 29 jun. 2019. 


\section{ReVIStg a d P puttg}

\} POLÍTICA DE IGUALDADE RACIAL - MADEIRA, M. Z. A. \}

DOI: $10.12957 /$ REP.2020.47221

IBGE. Desigualdades Sociais por Cor ou Raça no Brasil. Estudos e Pesquisas Informação Demográfica e Socioeconômica número 41. Rio de Janeiro: IBGE,2019.

JACCOUD, L. de B. Igualdade racial, Instituto de Pesquisa Econômica Aplicada (Ipea). Políticas sociais: acompanhamento e análise - vinte anos da constituição, Brasília, v. 3, n. 17, 2009a.

JACCOUD, L. de B. A construção de uma política de promoção da igualdade racial: uma análise dos últimos 20 anos. Brasília: Ipea, 2009b.

JACCOUD, L. de B.; BEGHIN, N. Desigualdades raciais no Brasil: um balanço da intervenção governamental. Brasília: Ipea, 2002.

MOTA, A. E. 80 anos do Serviço Social brasileiro: conquistas históricas e desafios na atual conjuntura. Serviço Social e Sociedade, São Paulo, n. 128, jan./abr. 2017.

NOGUEIRA, F. Governo Temer como restauração colonialista. Le Monde Diplomatique Brasil, Rio de Janeiro, 9 jan. 2017.

SANTOS, S. A. dos; SILVEIRA, M. Políticas de promoção da igualdade racial e ação afirmativa. Salto para o Futuro, v. 12, 2010.

SCHWARCZ, L. M.; STARLING, H. M. Brasil: uma biografia. São Paulo: Cia. das Letras, 2018.

SILVA, T. D. Gestão pública na zona do não ser: políticas públicas, igualdade racial e administração pública no Brasil. Administração Pública e Gestão Social, n. 9, v. 2, abr./jun. 2018.

SILVA, T. D. et al. Planejamento e Financiamento das Políticas de Igualdade Racial: possibilidades para o Plano Plurianual 2012- 2015. Nota técnica Disoc n. 7. Brasília: IPEA.2011SOUZA, J. A elite do atraso: da escravidão à Lava Jato. Rio de Janeiro: Leya, 2017.

THEODORO, M. (org.). As políticas públicas e a desigualdade racial no Brasil: 120 anos após a abolição. Brasília: Ipea, 2008.

DOI: $10.12957 /$ rep.2020.47221

Recebido em 04 de julho de 2019.

Aprovado para publicação em 10 de julho de 2019.

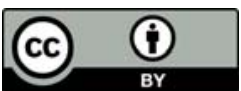

A Revista Em Pauta: Teoria Social e Realidade Contemporânea está licenciada com uma Licença Creative Commons Atribuição 4.0 Internacional. 